\title{
DIAGNOSIS AND SUCCESSFUL TREATMENT OF A UNIQUE FORM OF MALFUNCTION OF THE HEARTMATE LEFT VENTRICULAR ASSIST DEVICE
}

\author{
Salik Jahania, MD, David R. Onsager, MD, Tracey L. Weigel, MD, Charles C. Canver, MD, Robert B. Love, MD, and \\ Robert M. Mentzer, Jr., MD, Madison, Wis.
}

The treatment of patients with end-stage heart disease includes administration of digoxin, diuretics, and angiotensin-converting enzyme inhibitors. Persistence of symptoms despite maximal medical therapy may lead to initiation of intravenous inotropic support and ultimately heart transplantation. Because up to $30 \%$ of patients waiting for a heart transplant may die before a suitable donor organ becomes available, many individuals are considered candidates for temporary mechanical circulatory support with a left ventricular assist device (LVAD) as a bridge to transplantation. ${ }^{1}$ One such device, the Thermo Cardiosystems, Inc., HeartMate Implantable Pneumatic (TCI IP) LVAD (Woburn, Mass.), has been used successfully in North America and Europe. Although this device has been remarkably free of mechanical failure $^{2}$ we report a unique complication that could be catastrophic if not diagnosed and treated immediately.

Clinical summary. A 50-year-old man with idiopathic cardiomyopathy experienced shortness of breath and increasing fatigue for 2 years. With increasing dyspnea on exertion and tachycardia, he was admitted to a local hospital, given inotropic support, administered diuretics, and transferred to the University of Wisconsin Hospital and Clinics for evaluation and possible cardiac transplantation. Cardiac catheterization 3 months earlier had revealed minimal coronary artery disease and severe biventricular hypokinesis with an ejection fraction of 0.12 . On admission, blood pressure was $92 / 60 \mathrm{~mm} \mathrm{Hg}$, heart rate was 104 beats/min, and respiratory rate was 28 breaths/ min. Right heart catheterization revealed a cardiac index of $1.6 \mathrm{~L} / \mathrm{min}$ per square meter and a pulmonary capillary wedge pressure of $30 \mathrm{~mm} \mathrm{Hg}$. Despite infusions of dobutamine $(7.5 \mu \mathrm{g} / \mathrm{kg}$ per minute), dopamine $(5 \mu \mathrm{g} / \mathrm{kg}$ per minute), and milrinone $(0.5 \mu \mathrm{g} / \mathrm{kg}$ per minute $)$, the cardiac index increased only marginally $(1.9 \mathrm{~L} / \mathrm{min}$ per square meter). An intraaortic balloon pump was inserted and the patient was taken on an emergency basis to the operating room for implantation of a TCI IP LVAD.

From the Division of Cardiothoracic Surgery, University of Wisconsin School of Medicine, Madison, Wis.

Received for publication Jan. 14, 1997; accepted for publication Jan. 23, 1997.

Address for reprints: M. Salik Jahania, MD, Division of Cardiothoracic Surgery, Department of Surgery, University of Kentucky Medical Center, Room MN 264, 800 Rose St., Lexington, KY 40536-0084.

J Thorac Cardiovasc Surg 1997;114:143-4

Copyright (C) 1997 by Mosby-Year Book, Inc.

$0022-5223 / 97 \$ 5.00+0 \quad \mathbf{1 2 / 5 4 / 8 0 7 3 4}$
Three weeks later he was able to exercise up to 8 METS without difficulty. On return from an exercise session, the HeartMate console panel showed low flow and the alarm sounded. The interconnect cable and console were changed, but that had no effect on the console panel indicators. Failure of the device was suspected and the patient was given 10,000 IU of heparin to prevent stagnant blood from clotting inside the pump housing. He was immediately administered infusions of dobutamine (10 $\mu \mathrm{g} / \mathrm{kg}$ per minute) and milrinone $(0.5 \mu \mathrm{g} / \mathrm{kg}$ per minute) and was transferred to the intensive care unit. Physical examination revealed a blood pressure of $100 / 64 \mathrm{~mm} \mathrm{Hg}$ and a heart rate of 100 beats $/ \mathrm{min}$. The usual audible pumping sound was absent. On auscultation of the abdomen a gurgling sound was heard in the left upper quadrant. Chest and abdominal roentgenograms revealed free air under the diaphragm and presumptive evidence of disruption of the pneumatic drive line from

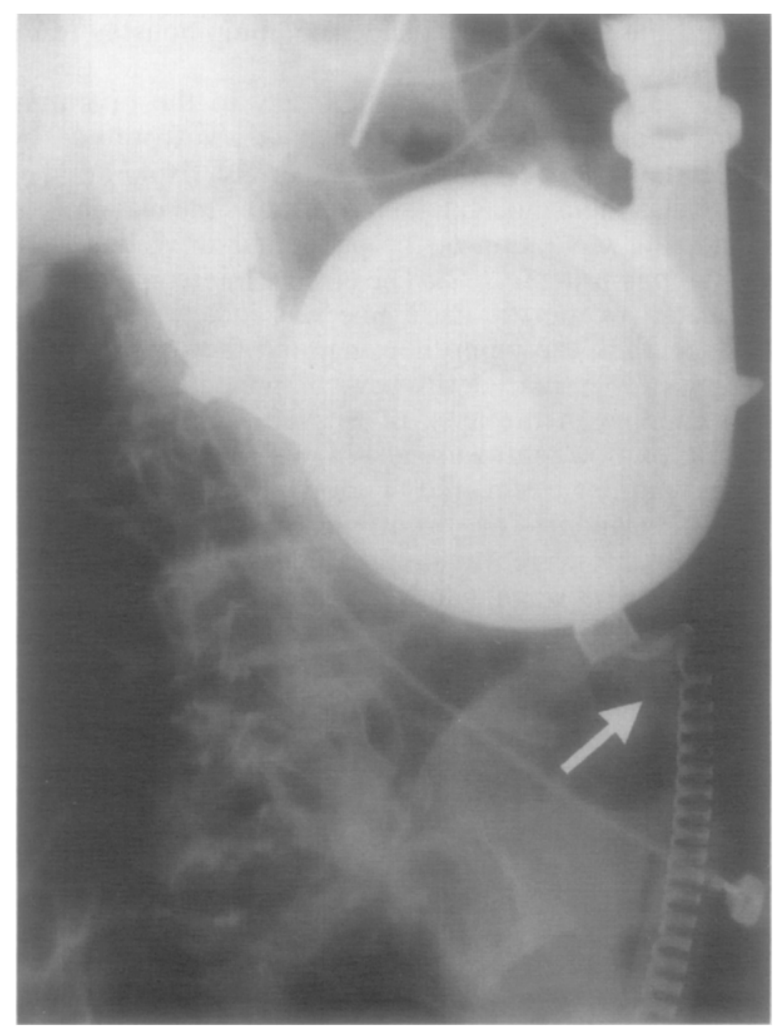

Fig. 1. Abdominal roentgenogram. Arrow indicates the separation site of the pneumatic drive line from the pump housing. The electric interconnect cable appears to be intact. 


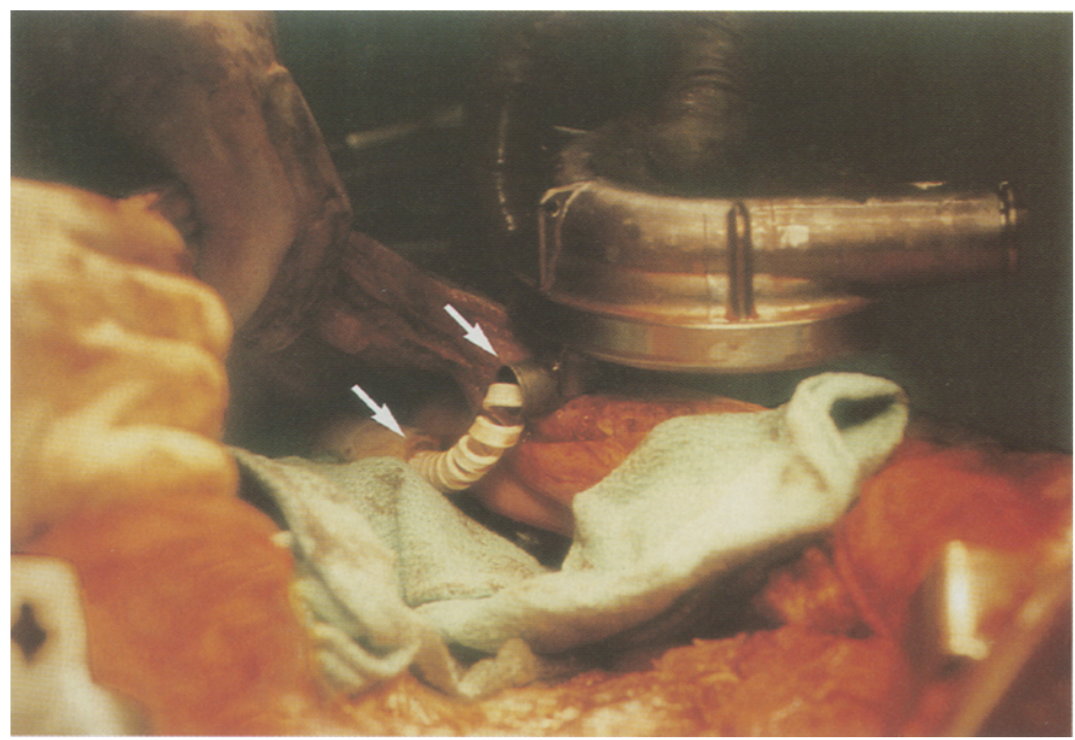

Fig. 2. Intraoperative photograph documenting the disrupted drive line and the intact electric interconnect cable.

the pump housing (Fig. 1). Fluoroscopic examination showed the pusher plate inside the pump housing to be immobile.

The patient was taken immediately to the operating room, where cardiopulmonary bypass was instituted by cannulation of the femoral vein and artery. Exploration of the mediastinum and abdomen confirmed the diagnosis of a complete separation of the pneumatic drive line from the pump housing (Fig. 2). The electric interconnect cable inside the pneumatic drive line was intact. The inflow valve conduit, the pump housing, and the outflow valve conduits were replaced with new components; the original inlet cannula in the apex of the left ventricle and the Dacron outflow graft were left in place and reused.

The patient recovered without complications and ultimately underwent orthotopic heart transplantation 4 months later. He was discharged from the hospital 2 weeks after his transplant operation, and at 4 months of follow-up he is free of rejection and has returned to work.

Discussion. With increased use of the HeartMate IP LVAD as a bridge to heart transplantation, it is possible that device malfunction will be encountered more fre- quently. This is the first report of separation of the pneumatic drive line from the pump housing. The manufacturer of the device has now modified the connection between the pneumatic drive line and the titanium pump housing. Ideally this will prevent further such complications. It is doubtful that the separation was related to exercise, because the pneumatic drive line was secure. Our exercise protocol for patients having a HeartMate LVAD remains unchanged. Although this type of device malfunction could be life threatening, rapid diagnosis and appropriate management can yield a satisfactory result.

\section{REFERENCES}

1. Frazier OH, Rose EA, McCarthy P, Burton N, Tector A, Levin $\mathrm{H}$, et al. Improved mortality and rehabilitation of transplant candidates treated with a long-term implantable left ventricular assist system. Ann Thorac Surg 1995;222: 327-36.

2. Jaski BE, Branch KR, Dasse KA, Dembitsky W. Diagnosis and treatment of complications in patients implanted with a TCI left ventricular assist device. J Intervent Cardiol 1995;8:275-82. 